\title{
Bidirectional Modulation of Intrinsic Excitability in Rat Prelimbic Cortex Neuronal Ensembles and Non-Ensembles after Operant Learning
}

\author{
Leslie R. Whitaker, ${ }^{1}$ Brandon L. Warren, ${ }^{1}{ }^{\oplus}$ Marco Venniro, ${ }^{1}$ Tyler C. Harte, ${ }^{1}$ Kylie B. McPherson, ${ }^{1}$ Jennifer Beidel, ${ }^{1}$ \\ 일ennifer M. Bossert, ${ }^{1}$-Yavin Shaham, ${ }^{1}$ Antonello Bonci, ${ }^{2}$ and ${ }^{\circledR B}$ Bruce T. Hope ${ }^{1}$ \\ ${ }^{1}$ Behavioral Neuroscience Research Branch and ${ }^{2}$ Cellular Neurobiology Research Branch, Intramural Research Program, National Institute on Drug Abuse, \\ National Institutes of Health, Baltimore, Maryland 21224
}

Learned associations between environmental stimuli and rewards drive goal-directed learning and motivated behavior. These memories are thought to be encoded by alterations within specific patterns of sparsely distributed neurons called neuronal ensembles that are activated selectively by reward-predictive stimuli. Here, we use the Fos promoter to identify strongly activated neuronal ensembles in rat prelimbic cortex (PLC) and assess altered intrinsic excitability after $10 \mathrm{~d}$ of operant food self-administration training ( $1 \mathrm{~h} / \mathrm{d})$. First, we used the Daun02 inactivation procedure in male FosLacZ-transgenic rats to ablate selectively Fos-expressing PLC neurons that were active during operant food self-administration. Selective ablation of these neurons decreased food seeking. We then used male FosGFPtransgenic rats to assess selective alterations of intrinsic excitability in Fos-expressing neuronal ensembles (FosGFP ${ }^{+}$) that were activated during food self-administration and compared these with alterations in less activated non-ensemble neurons (FosGFP ${ }^{-}$). Using whole-cell recordings of layer $\mathrm{V}$ pyramidal neurons in an ex vivo brain slice preparation, we found that operant self-administration increased excitability of FosGFP ${ }^{+}$neurons and decreased excitability of FosGFP ${ }^{-}$neurons. Increased excitability of FosGFP ${ }^{+}$neurons was driven by increased steady-state input resistance. Decreased excitability of $\mathrm{FosGFP}^{-}$neurons was driven by increased contribution of small-conductance calcium-activated potassium (SK) channels. Injections of the specific SK channel antagonist apamin into PLC increased Fos expression but had no effect on food seeking. Overall, operant learning increased intrinsic excitability of PLC Fosexpressing neuronal ensembles that play a role in food seeking but decreased intrinsic excitability of Fos ${ }^{-}$non-ensembles.

Key words: electrophysiology; Fos; intrinsic plasticity; motivated behavior; reward learning; transgenic rat

Significance Statement

Prefrontal cortex activity plays a critical role in operant learning, but the underlying cellular mechanisms are unknown. Using the chemogenetic Daun02 inactivation procedure, we found that a small number of strongly activated Fos-expressing neuronal ensembles in rat PLC play an important role in learned operant food seeking. Using GFP expression to identify Fos-expressing layer $\mathrm{V}$ pyramidal neurons in prelimbic cortex (PLC) of FosGFP-transgenic rats, we found that operant food self-administration led to increased intrinsic excitability in the behaviorally relevant Fos-expressing neuronal ensembles, but decreased intrinsic excitability in Fos ${ }^{-}$neurons using distinct cellular mechanisms.

\section{Introduction}

In operant learning, learned associations between rewards and stimuli predictive of reward control goal-directed behaviors.

Received Dec. 7, 2016; revised July 10, 2017; accepted July 18, 2017.

Author contributions: L.R.W., Y.S., A.B., and B.T.H. designed research; L.R.W., B.L.W., T.C.H., K.B.M., and J.M.B. performed research; L.R.W. and J.M.B. analyzed data; L.R.W., M.V., T.C.H., Y.S., and B.T.H. wrote the paper.

This work was supported by the Intramural Research Program, National Institute on Drug Abuse, National Institutes of Health. We thank Rajtarun Madangopal for helpful discussions regarding the data and manuscript.

The authors declare no competing financial interests.

Correspondence should be addressed to Leslie R. Whitaker, Behavioral Neuroscience Research Branch, Intramural Research Program, National Institute on Drug Abuse, National Institutes of Health, 251 Bayview Blvd., Baltimore, MD 21214. E-mail: leslie.ramsey@nih.gov.
Based on the "cell assembly" hypothesis (Hebb, 1949), learned associations are thought to be stored within sparsely distributed sets of neurons called neuronal ensembles that are activated selectively by behaviorally relevant cues. Studies using in vivo electrophysiology and calcium imaging have provided support for this hypothesis, identifying populations of neurons that were activated selectively by specific stimuli during sensory processing, associative learning, and goal-directed behaviors (Matsumoto et al., 2007; Euston et al., 2012; Pinto and Dan, 2015). 
Fos is an immediate early gene commonly used as an indicator of strong neuronal activation (Morgan and Curran, 1986). Recently, we and others developed novel Fos promoter-based techniques to identify and manipulate selectively neurons that were strongly activated during operant or Pavlovian learned behaviors (Reijmers et al., 2007; Koya et al., 2009; Liu et al., 2012; Cruz et al., 2013). We developed the chemogenetic Daun02 inactivation procedure to ablate selectively Fos-expressing ensembles in FosLacZtransgenic rats and assess their causal role in learned behaviors (Koya et al., 2009; Cruz et al., 2013; Cruz et al., 2015). The transgene contains a Fos promoter that induces coexpression of $\beta$-galactosidase ( $\beta$-Gal) with endogenous Fos protein in strongly activated neurons. When the inactive prodrug Daun02 is injected into a brain region, $\beta$-Gal that was expressed in recently activated neurons rapidly converts Daun02 into daunorubicin, which initially reduces neuronal excitability (Engeln et al., 2016) and subsequently causes apoptosis that permanently ablates the $\beta$-Gal-expressing neurons (Pfarr et al., 2015). Using this procedure, we and others have demonstrated causal roles for Fosexpressing neuronal ensembles in operant food (Suto et al., 2016; Warren et al., 2016) and drug (Bossert et al., 2011; Fanous et al., 2012; Cruz et al., 2014; Pfarr et al., 2015; Funk et al., 2016; de Guglielmo et al., 2016; Caprioli et al., 2017) seeking, as well as in Pavlovian associations between drugs and environmental cues (Koya et al., 2009). These studies support the hypothesis that learned associations are encoded by behaviorally activated Fosexpressing ensembles, whereas the majority of less activated Fos neurons likely play a lesser role in encoding learned associations.

Many studies have examined electrophysiological alterations after operant or Pavlovian learning (Brons and Woody, 1980; Beck and Yaari, 2008; Kourrich et al., 2015; Oh and Disterhoft, 2015). However, nearly all of these studies assessed alterations with randomly selected neurons regardless of the activity during behavior. These previous studies most likely assessed alterations in neurons that were not significantly activated during the learned behavior and only indirectly involved in encoding the learned associations. Very few recent studies have examined molecular and cellular alterations induced within Fos-expressing neuronal ensembles that were activated during behavior. These studies identified unique synaptic alterations (Koya et al., 2012; Whitaker et al., 2016) selectively within Fos-expressing ensembles after Pavlovian learning. One recent study examined alterations of intrinsic excitability in Fos-expressing ensembles during Pavlovian approach behavior (Ziminski et al., 2017). However, intrinsic excitability in Fos-expressing ensembles has not been examined after operant learning.

In this study, we first used the Daun02 inactivation procedure to assess a causal role for Fos-expressing neuronal ensembles in rat prelimbic cortex (PLC) in operant food-seeking behavior. The PLC is a functionally diverse structure within the prefrontal cortex that plays a critical role in goal-directed behavior and learning (Baldwin et al., 2002; Corbit and Balleine, 2003; Fujii and Graybiel, 2003; Euston et al., 2012) and is active during the presentation of reward or reward-predictive cues (Watanabe, 1996; Matsumoto et al., 2007; Moorman and Aston-Jones, 2015; Pinto and Dan, 2015). We then used an ex vivo brain slice preparation in FosGFP-transgenic rats (Cifani et al., 2012) to identify Fos/GFP-expressing neurons that were strongly activated during operant food self-administration and assessed intrinsic excitability in FosGFP ${ }^{+}$and FosGFP ${ }^{-}$neurons. Electrophysiological alterations induced after associative learning have been identified previously in PLC neurons, but these neurons were selected regardless of their activity state during behavior (Song et al., 2015;
Giustino et al., 2016). Intrinsic excitability is an important factor in the integration of afferent inputs that select neurons to be part of an ensemble (Kourrich et al., 2015) and thus in the formation of neuronal ensembles underlying learned associations in operant learning.

\section{Materials and Methods}

Subjects. We used a total of 50 male Long-Evans rats (Charles River Laboratories), 42 FosLacZ-transgenic rats (Sprague Dawley background) (Koya et al., 2009), and 46 FosGFP-transgenic rats on a Long-Evans background (Cifani et al., 2012), each weighing between 200 and $450 \mathrm{~g}$ at the beginning of an experiment. Rats were maintained on a $12 \mathrm{~h}$ reversed light/dark cycle and were individually housed for the duration of the experiment. Training sessions were generally conducted in the morning during the first few hours of the dark cycle. Food and water were available ad libitum throughout the duration of all experiments, except for two FosGFP rats and 13 FosLacZ rats. In these rats, food was restricted to $20 \mathrm{~g} / \mathrm{d}$ to facilitate training and then they were returned to a free-feeding schedule. We excluded five rats for misplaced cannulas (Experiment 2).

Intracranial surgery. We anesthetized FosLacZ-transgenic rats with isoflurane and implanted permanent guide cannulas (23 gauge; Plastics One) bilaterally $1 \mathrm{~mm}$ above the PLC. The nose bar was set at $-3.3 \mathrm{~mm}$ and the coordinates for the PLC were anteroposterior $+3.0 \mathrm{~mm}$, mediolateral $\pm 1.5 \mathrm{~mm}\left(10^{\circ}\right.$ angle), and dorsoventral $-3.5 \mathrm{~mm}$ (Bossert et al., 2011; Warren et al., 2016). Cannulas were fixed to the rat's skull with dental cement and jeweler's screws. Ketoprofen $(2.5 \mathrm{mg} / \mathrm{kg}$, s.c.) was administered after surgery to relieve pain and rats were allowed to recover for 5-7 d before initiating operant training.

Intracranial injections. Daun02 was obtained from Sequoia Research Products and dissolved the prodrug in vehicle solution containing 5\% DMSO, 6\% Tween 80, and 89\% 0.1 M PBS (Koya et al., 2009; Bossert et al., 2011). Apamin was obtained from Tocris Bioscience (catalog \#1652) and dissolved in a saline vehicle solution for a final concentration of $1 \mu \mathrm{M}$ (Cannady et al., 2017). Vehicle, Daun02 ( $2 \mu \mathrm{g} / 0.5 \mu \mathrm{l} / \mathrm{side})$, or apamin ( $0.5 \mu \mathrm{g} / 0.5 \mu \mathrm{l} / \mathrm{side}$ ) were injected using a syringe pump (Harvard Apparatus) and $10 \mu \mathrm{l}$ Hamilton syringes that were attached via polyethylene-50 tubing to 30 gauge injectors (Plastics One) that extended $1 \mathrm{~mm}$ beyond the guide cannula. The injection duration was $1 \mathrm{~min}$ and injectors were left in place $1 \mathrm{~min}$ before removal.

Operant conditioning of lever pressing for palatable food pellets. Rats were trained and tested in Med Associates self-administration chambers containing 2 retractable levers located $7 \mathrm{~cm}$ above the grid floor and a red house light. Presses on the active retractable lever activated the pellet dispenser, whereas presses on the inactive retractable lever had no programmed consequences.

Each experiment consisted of a food self-administration session (10 d) on a fixed-ratio 1 reinforcement schedule with a $20 \mathrm{~s}$ timeout. Rats were trained to lever press for palatable food pellets ( $45 \mathrm{mg}$; TestDiet, catalog \#1811155) (Calu et al., 2014) and no additional cues were provided. Before the initiation of training, rats were preexposed to palatable food pellets to avoid neophobia during operant sessions.

Immunohistochemistry and staining. Ninety minutes after the initiation of the test session, rats were deeply anesthetized with isoflurane (90 s) and perfused with PBS, followed by $4 \%$ paraformaldehyde (PFA). The brains were postfixed for an additional $90 \mathrm{~min}$ in PFA and incubated in $30 \%$ sucrose in PBS at $4^{\circ} \mathrm{C}$ for $2-3 \mathrm{~d}$ before freezing in dry ice and storing at $-80^{\circ} \mathrm{C}$. Coronal brain slices $(40 \mu \mathrm{m})$ were then cut using a cryostat (Leica CM1850 UV).

For Fos immunohistochemistry, sections were washed in PBS, blocked in $3 \%$ normal goat serum (NGS) in PBS with $0.25 \%$ Triton X-100 (PBS$\mathrm{Tx})$, and incubated for $24 \mathrm{~h}$ at $4^{\circ} \mathrm{C}$ with anti-Fos antibody (1:8000 dilution; Cell Signaling Technology, catalog \# 2250, RRID:AB_2247211) in blocking solution. Sections were then washed in PBS and incubated with biotinylated goat anti-rabbit secondary antibody (1:600 dilution; Vector Laboratories, catalog \#BA-1000) in PBS-Tx and 1\% NGS for $2 \mathrm{~h}$. After another wash in PBS, sections were incubated in avidin-biotin-peroxidase complex (ABC Elite kit, PK-6100; Vector Laboratories) in PBS containing $0.5 \%$ Triton X-100. Sections were then developed in $3,3^{\prime}$ - 
diaminobenzidine (DAB) for $140 \mathrm{~s}$ and mounted onto chromalumgelatin-coated slides. Once dry, slides were dehydrated through a graded series of alcohol (30\%, 60\%, 90\%, 100\%, 100\% ethanol) and cleared with Citrasolv (Fisher Scientific) before coverslipping with Permount (Sigma-Aldrich).

To determine the relative size of the neuronal ensembles that were activated after food self-administration training, PLC sections from wildtype rats were double-labeled for Fos and the general neuronal marker protein NeuN. Sections were washed in PBS, blocked in 3\% NGS in PBS with $0.25 \%$ Triton X-100 (PBS-Tx), and incubated for $24 \mathrm{~h}$ at $4^{\circ} \mathrm{C}$ with monoclonal Fos antibody (1:2000 dilution; Cell Signaling Technology, catalog \# 2250, RRID:AB_2247211) and NeuN mouse antibody (1:1000 dilution; Millipore, catalog \#MAB377, RRID:AB_2298772) in blocking solution. Sections were then washed in PBS and incubated with Alexa Fluor 488 anti-rabbit and Alexa Fluor 568 anti-mouse secondary antibodies (1:600 dilution; Invitrogen, RRID:A-21206, RRID:A-11004) in PBS-Tx and $1 \%$ NGS for $2 \mathrm{~h}$. After another wash in PBS, sections were mounted and coverslipped with Vectashield (Vector Laboratories, catalog \#H-1400).

For X-gal staining, sections were washed in PBS and incubated in X-gal reaction solution containing the following (in mM): $5 \mathrm{~K}_{4} \mathrm{Fe}(\mathrm{CN})_{6} \cdot 3 \mathrm{H}_{2} \mathrm{O}, 5$ $\mathrm{K}_{3} \mathrm{Fe}(\mathrm{CN})_{6}$, and $2.4 \mathrm{X}$-gal for $4-5 \mathrm{~h}$ at $37^{\circ} \mathrm{C}$ while shaking. Finally, sections were washed again in PBS before mounting onto chromalumgelatin-coated slides. Once dry, slides were dehydrated through a graded series of alcohol (30\%, 60\%, 90\%, 100\%, 100\% ethanol) and cleared with Citrasolv (Fisher Scientific) before coverslipping with Permount (Sigma-Aldrich).

Bright-field images of immunoreactive cells in the prelimbic cortex (PLC) were captured digitally using an EXi Aqua camera (QImaging) attached to a Zeiss Axioskop 2 microscope at $200 \times$ magnification and iVision software for Macintosh, version 4.0.15 (Biovision). Labeled neurons were counted by an investigator blinded to the test conditions from two sections (bilateral) per rat. X-gal-stained cells and DAB-labeled Fos cells were counted automatically and NeuN-labeled neurons manually. The counts were averaged so that each rat was an $n$ of 1 for each brain area.

Ex vivo brain slice electrophysiology. Ninety minutes after the initiation of the final operant training session, FosGFP-transgenic rats were deeply anesthetized with isoflurane (60-90 s) and then rapidly decapitated. Coronal sections $(250-280 \mu \mathrm{m})$ containing medial prefrontal cortex were cut using a vibratome (Leica VT1000) in an ice-cold cutting solution containing the following (in mM): 92 NMDG, 20 HEPES, 25 glucose, $30 \mathrm{NaHCO}_{3}, 1.2 \mathrm{NaH}_{2} \mathrm{PO}_{4}, 2.5 \mathrm{KCl}, 5 \mathrm{Na}$-ascorbate, $3 \mathrm{Na}$-pyruvate, 2 thio-urea, $10 \mathrm{MgSO}_{4}$, and $0.5 \mathrm{CaCl}_{2}$, saturated with $95 \% \mathrm{O}_{2} 5 \% \mathrm{CO}_{2}, \mathrm{pH}$ 7.3-7.4, 305-310 mOsm $/ \mathrm{kg}$. Slices were allowed to recover for a minimum of $30 \mathrm{~min}$ at $22^{\circ} \mathrm{C}$ in artificial CSF containing the following (in $\mathrm{mm}$ ): $126 \mathrm{NaCl}, 2.5 \mathrm{KCl}, 1.2 \mathrm{MgCl}_{2}, 2.4 \mathrm{CaCl}_{2}, 1.2 \mathrm{NaH}_{2} \mathrm{PO}_{4}, 21.4$ $\mathrm{NaHCO}_{3}, 11.1$ glucose, $3 \mathrm{Na}$-pyruvate, and $1 \mathrm{Na}$-ascorbate. Recordings were performed at $32-35^{\circ} \mathrm{C}$ in the same solution that was bath-perfused at $2-3 \mathrm{ml} / \mathrm{min}$. The intracellular solution contained the following (in mM): $115 \mathrm{~K}$-gluconate, $20 \mathrm{KCl}, 1.5 \mathrm{MgCl}_{2}, 10 \mathrm{HEPES}, 0.025$ EGTA, 2 Mg-ATP, $0.2 \mathrm{Na}_{2}$-GTP, and $10 \mathrm{Na}_{2}$-phosphocreatine, $\mathrm{pH}$ 7.2-7.3, 285$290 \mathrm{mOsm} / \mathrm{kg}$.

FosGFP-expressing (Fos + ) cells were identified using scanning-disk confocal microscopy (Olympus FV1000) and differential interference contrast optics was used to identify and patch pyramidal neurons visually in PLC. An Axopatch 200B amplifier (Molecular Devices) and Axograph $\mathrm{X}$ software (Axograph Scientific) were used to record and collect the data, which were filtered at $10 \mathrm{kHz}$ and digitized at $4-20 \mathrm{kHz}$. Series resistance $(R \mathrm{~s})$ was monitored with injection of hyperpolarizing current $(-20 \mathrm{pA}$, $500 \mathrm{~ms}$ ) and data were excluded if $R$ s changed $>20 \%$ during data acquisition. Input resistance was calculated from the slope of the linear portion of the $I-V$ curve after hyperpolarizing current injections $(-20$ to -100 pA, $500 \mathrm{~ms},-20 \mathrm{pA}$ increments). Rheobase current was measured using a series of depolarizing current steps (500 ms duration, $0-320 \mathrm{pA},+20$ pA increments). Percentage sag current was calculated as the percentage change from peak to steady-state voltage deflection after injecting hyperpolarizing current steps ( $500 \mathrm{~ms}$ duration, $-150 \mathrm{pA}$ ). Repetitive firing was measured using depolarizing current steps (500 ms duration, 50-500 $\mathrm{pA},+20 \mathrm{pA}$ increments). Spike frequency adaptation was measured as a ratio of the final to the first interstimulus interval after a $500 \mathrm{~ms}, 330 \mathrm{pA}$ current step. Action potential (AP) threshold was measured at the point of inflection when the slope exceeds $10 \mathrm{mV} / \mathrm{ms}$. AP amplitude was measured as the voltage change from threshold to AP peak. AP half-width was measured as the latency from threshold to AP peak. AP Latency is the time from onset of rheobase current step to AP threshold. Fast afterhyperpolarization (fAHP) was identified as the peak amplitude of the current 3-4 ms after AP threshold. Medium AHP (mAHP) was measured as the peak amplitude of the current 15-100 ms after AP threshold. In cells that did not have a peak in that range, the value of the current peak at $15 \mathrm{~ms}$ was used for data analysis. For data collected in Figure 3, $C-F$, a stable baseline was obtained using both rheobase and repetitive firing protocols and then apamin (300 $\mathrm{nm}$ ) was bath applied for $10 \mathrm{~min}$, followed by a 5 min washout period.

Experimental design and statistical analysis. Electrophysiology data were collected using Axograph X and WinWCP software and analyzed using Axograph X and GraphPad Prism (version 6.0). Behavioral data were analyzed using GraphPad Prism. For experiments containing more than two groups or more than one factor, factorial ANOVAs were used. For experiments comparing the mean of two groups, unpaired $t$ tests were used. When ANOVAs indicated a significant interaction $(p<0.05)$, Fisher PLSD post hoc analyses were performed.

Experiment 1: Food self-administration and Fos expression in PLC. Fos immunoreactivity was examined after either 1 or $10 \mathrm{~d}$ of food selfadministration training to determine how neuronal activity, as assessed by Fos in the PLC changes over the course of operant training. Four groups of wild-type rats (no test-day $1, n=6$; no test-day 10, $n=6$; test-day $1, n=10$; and test-day $10, n=10$; see Fig. $1 A$ ) were used in a $2 \times 2$ experimental design with training days $(1,10)$ and test (test, no test) as the between-subjects factors. Rats were trained for $1 \mathrm{~h} / \mathrm{d}$ for either 1 or $10 \mathrm{~d}$ (see Fig. 1A). No-test control groups received identical training (either 0 or $9 \mathrm{~d}$ of food self-administration training) but remained in the home cage on test day (day 1 or 10). Thirty minutes after the end of the self-administration session, rats were anesthetized, transcardially perfused with PBS and 4\% PFA, and brains were removed for subsequent analysis of Fos expression in PLC.

Experiment 2: Daun02 inactivation in PLC after food self-administration training in FosLacZ-transgenic rats. The role of PLC Fos-expressing neuronal ensembles in the expression of food-seeking behavior was assessed. Two groups of FosLacZ-transgenic rats and rats injected with Daun02 versus vehicle were compared (vehicle, $n=19$; Daun02, $n=18$; see Fig. $1 D)$. All rats were trained to self-administer palatable food pellets as described above for $9 \mathrm{~d}$. On the $10^{\text {th }}$ day of training, which we call "induction day," rats were separated into two groups and either Daun02 $(2 \mu \mathrm{g} / 0.5 \mu \mathrm{l} / \mathrm{side}$ ) or vehicle was injected into PLC $30 \mathrm{~min}$ after the end of the training session (Koya et al., 2009; Bossert et al., 2011; Fanous et al., 2012; Cruz et al., 2014; Caprioli et al., 2017). Rats were returned to their home cages, where they remained for $3 \mathrm{~d}$ to allow Daun02 inactivation to take full effect. On test day, 3 d later, rats were given a 30 min test in the operant chamber under extinction conditions to determine whether PLC neuronal ensembles play a causal role in the expression of food-seeking behavior. Sixty minutes after the end of the test session, rats were anesthetized and transcardially perfused with PBS and 4\% PFA for subsequent analysis of $\beta$-gal expression. Rats were tested for operant food seeking in the absence of the food reward because we wanted to determine whether the Daun02 manipulation would decrease the motivation to seek the operant reward and associated neuronal activity in the absence of the potential confounding factors of within-session food intake and satiety.

Experiment 3: Intrinsic properties of Fos-expressing neuronal ensembles in PLC after food self-administration. Ex vivo brain slice electrophysiology was performed in FosGFP-transgenic rats to identify electrophysiological alterations that may play a role in the expression of operant learning in FosGFP $^{+}$and FosGFP ${ }^{-}$neurons after food self-administration. Four groups of rats in a $2 \times 2$ experimental design with training days $(1,10)$ and test (test, no test) as the between-subjects factors ( $n=4-11$ /group) were used. However, the primary statistical analyses was performed within the test groups using the between-subjects factors of training day $(1,10)$ and FosGFP expression $\left(\right.$ FosGFP $^{+}$, FosGFP $\left.^{-}\right)$because our pri- 
mary interest was in the comparison between the electrophysiological properties of the active and less active/inactive neurons in the test groups. The no test group was included to determine whether the characteristics of the Fos ${ }^{-}$ neurons were consistent between the test and no test groups. Fos ${ }^{+}$neurons in the test group could not be compared with Fos ${ }^{+}$neurons in the no test (home cage) groups because these populations are likely to be completely different populations of Fos ${ }^{+}$neurons. FosGFP rats were trained to self-administer food for either 1 or $10 \mathrm{~d}$ as described for Experiment 1. For test group rats, one rat per day was anesthetized 30 min after the end of the operant training session, rapidly decapitated, and the brain taken for ex vivo brain slice electrophysiological recordings. Rats in the no test groups (home cage controls) were taken directly from their home cages before their brains were taken for electrophysiological recordings. Detailed slicing and recording procedures are described above.

Experiment 4: Intra-PLC injections of the SK channel antagonist apamin before a test for the expression of food-seeking behavior. Two groups of wild-type rats were compared with rats intracranially injected with apamin versus vehicle (vehicle: $n=9$, apamin $n=9$; see Fig. $6 A$ ). Rats were trained to lever press for palatable food reward in $1 \mathrm{~h}$ training sessions each day for $12 \mathrm{~d}$. On the $13^{\text {th }}$ day, either vehicle or apamin was injected into the PLC 5 min before a 30 min test session conducted under extinction conditions. Sixty minutes after the end of the self-administration session, rats were anesthetized, transcardially perfused with PBS and $4 \%$ PFA, and their brains removed for subsequent analysis of Fos expression in the PLC. Rats were tested for operant food seeking in the absence of the food reward because we wanted to determine whether apamin would change the motivation to seek the operant reward and associated neuronal activity in the absence of the potential confounding factors of withinsession food intake and satiety.

\section{Results}

Food self-administration behavior and Fos expression

We trained male rats (Fig. $1 A, B$ ) to selfadminister palatable food pellets for 1 or $10 \mathrm{~d}$ (Fig. 1A). During training, active lever presses led to delivery of a single food pellet, whereas inactive lever presses had no consequences. The rats increased lever pressing over the course of $10 \mathrm{~d}\left(F_{(9,243)}=\right.$ $10.19, p<0.0001$; Fig. $1 B)$. To assess altered neural activation over training, we measured Fos expression in PLC after 1 or $10 \mathrm{~d}$ of food self-administration training (test groups) and compared it with Fos expression in home cage control rats (no test groups) that were taken directly from their home cages after either no prior training (day 1 no test control) or on test day after $9 \mathrm{~d}$ of previous food self-admi-
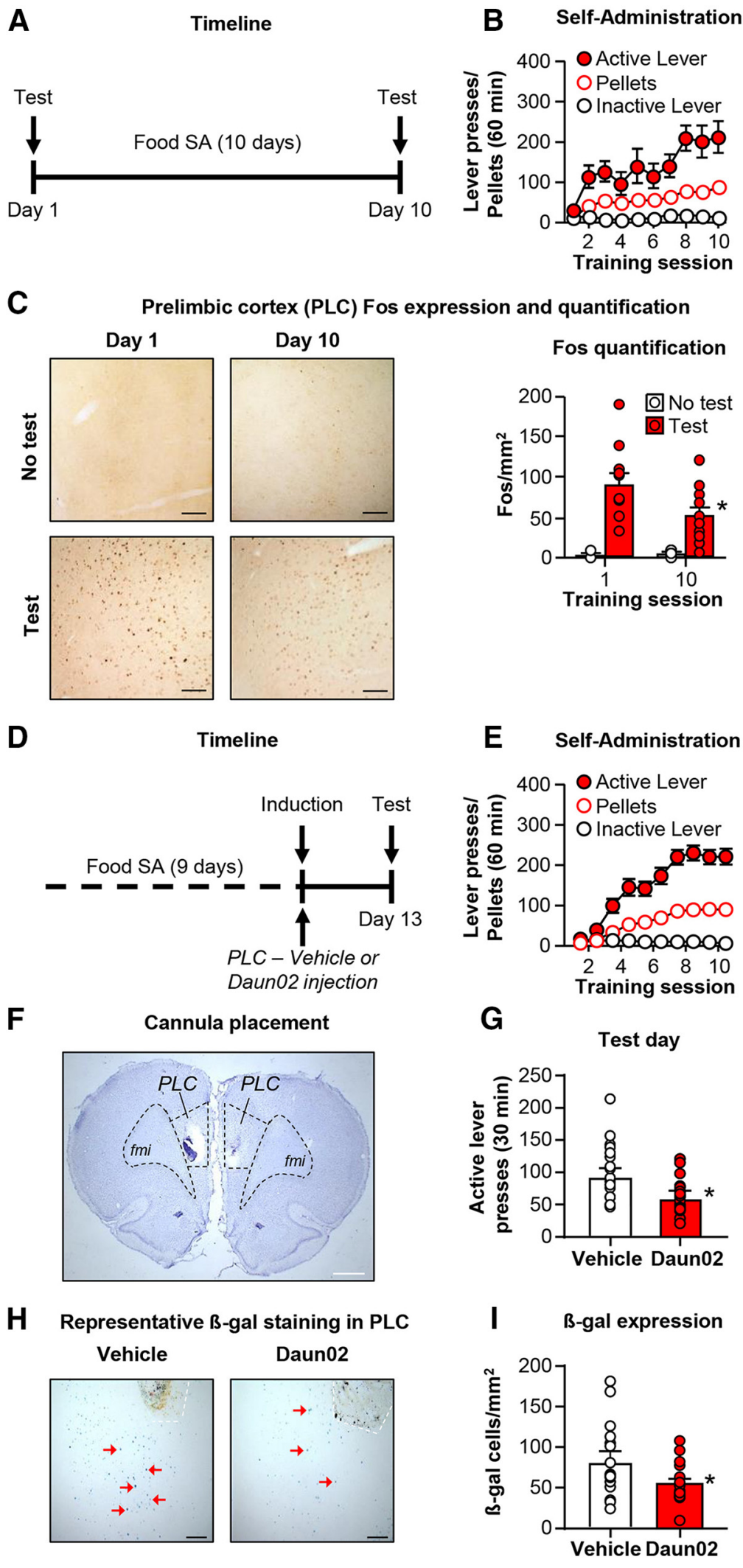

Figure 1. Fos-expressing neuronal ensembles play a causal role in the expression of food-seeking behavior. $A, B$, Experimental timeline $(\boldsymbol{A})$ and self-administration data $(\boldsymbol{B})$ in wild-type rats. $\boldsymbol{C}$, Representative images (scale bar is $20 \mu \mathrm{m}$ ) and quantification of Fos ${ }^{+}$PLC neurons $\left({ }^{*} p<0.05\right.$; no test-day $1: n=6$, no test-day 10: $n=6$, test-day $1: n=10$, test- day 10: $\left.n=10\right)$. Scale bar, $20 \mu \mathrm{m}$. $\boldsymbol{D}-\boldsymbol{F}$, Experimental timeline $(\boldsymbol{D})$ and food self-administration $(\boldsymbol{E})$. $\boldsymbol{F}$, Cannula placement for Daun02 inactivation experiment. $\boldsymbol{H}, \boldsymbol{I}$, Lever-pressing behavior in FosLacZ rats on test day $\left({ }^{*} p<0.05\right.$; vehicle: $n=19$, Daun02: $\left.n=18\right)$. Shown are representative images of B-gal staining $(\boldsymbol{H})$ and B-gal quantification $(\boldsymbol{I})$ after Daun02 inactivation $\left(^{*} p<0.05\right.$; vehicle: $n=16$, Daun02: $n=16)$. Scale bar, $20 \mu \mathrm{m}$. 
nistration training (day 10 no test control) (Fig. 1C). On test days 1 and 10, the self-administration training session increased Fos expression levels in PLC of the test groups relative to levels in the no test groups (Fig. $1 C$ ). The statistical analysis showed main effects of training day $\left(F_{(1,28)}=29.64, p<0.0001\right)$; the interaction between test condition and training day was not significant $\left(F_{(1,28)}=2.63, p=0.12\right)$. Using Fos + NeuN double labeling, we found that $\sim 5 \%$ of neurons in PLC coexpressed Fos and NeuN after $10 \mathrm{~d}$ of food self-administration training. Therefore, only a small subset of the total neuronal population in PLC expressed Fos after the food self-administration session.

\section{Selective ablation of Fos-expressing neuronal ensembles in} PLC after food self-administration using Daun02 inactivation To determine whether Fos-expressing neuronal ensembles in PLC play a critical role in the expression of food-seeking behavior, we used the Daun02 inactivation procedure in FosLacZ rats to ablate selectively Fos-expressing neurons in PLC that were activated during the self-administration training session on day 10 (Fig. 1D). The transgenic rats learned to self-administer food in a manner similar to the wild-type rats (Fig. $1 E$ ). Immediately before the intra-PLC injections on day 10, active lever pressing was not different between the groups that would later receive vehicle or Daun02 injections $\left(t_{(35)}=1.24, p=0.22\right)$. The effects of Daun02 injections on lever pressing were assessed $3 \mathrm{~d}$ later under extinction conditions (Fig. 1G). Daun02 decreased active lever pressing on test day $\left(t_{(29.15)}=2.5, p=0.018\right)$. Daun02 also decreased the number of $\beta$-gal-labeled neurons in $\operatorname{PLC}\left(t_{(23.13)}=\right.$ $2.18, p=0.04$; Fig. $1 I)$, which confirmed successful inhibition of the activated neuronal ensemble in PLC. Together, these data indicate that Fos-expressing neuronal ensembles of the PLC play a causal role in expression of food-seeking behavior.

Bidirectional modulation of intrinsic excitability in FosGFP ${ }^{+}$ and FosGFP ${ }^{-}$PLC neurons after food self-administration We compared intrinsic properties of FosGFP ${ }^{+}$and FosGFP ${ }^{-}$ neurons (Fig. 2A) in FosGFP-transgenic rats that received either 1 or $10 \mathrm{~d}$ of food self-administration training (test groups) and in rats that remained in their home cages on test day (no test groups). As mentioned previously, we did not perform a three-way ANOVA using test, training, and FosGFP expression as factors because we could not compare $\mathrm{Fos}^{+}$neurons in the test group with $\mathrm{Fos}^{+}$neurons in the no test (home cage) groups as these are likely to be different populations of $\mathrm{Fos}^{+}$neurons. In addition, with a very small number of FosGFP ${ }^{+}$neurons in the no test groups, we could not always detect enough activated neurons in these groups for reliable electrophysiological and statistical analyses.

Intrinsic excitability of FosGFP ${ }^{+}$neurons in the test groups increased from 1 to $10 \mathrm{~d}$ of training $\left(F_{(28,434)}=1.7, p=0.015\right)$, whereas intrinsic excitability of FosGFP ${ }^{-}$neurons decreased from 1 to $10 \mathrm{~d}$ of training $\left(F_{(28,476)}=3.9, p<0.001\right.$; Fig. $\left.2 C\right)$. Intrinsic excitability of FosGFP ${ }^{-}$neurons in the no test groups decreased from 1 to $10 \mathrm{~d}$ of training $\left(F_{(14,294)}=2.8, p<0.001\right.$; Fig. $2 C$ ). Altogether, these data indicate that intrinsic excitability is upregulated in $\mathrm{FosGFP}^{+}$neuronal ensembles in PLC during food self-administration learning and concurrently downregulated in the less activated or nonactivated FosGFP ${ }^{-}$neurons. Importantly, baseline excitability was not different between Fos$\mathrm{GFP}^{+}$and FosGFP ${ }^{-}$neurons in PLC of the no test rats on day 1 before any food self-administration training $\left(F_{(14,364)}=0.42\right.$, $p=0.97)$. This suggests there are no preexisting differences in intrinsic excitability between FosGFP ${ }^{+}$and FosGFP ${ }^{-}$neurons that predisposes them to being incorporated into activated neuronal ensembles.

\section{Alterations of subthreshold membrane properties in FosGFP $^{+}$and FosGFP ${ }^{-}$PLC neurons after food self-administration}

We assessed subthreshold membrane properties in FosGFP ${ }^{+}$and FosGFP $^{-}$neurons in PLC to determine whether a change in these properties could account for the alterations in intrinsic excitability described above. Example traces demonstrate how input resistance was measured in Figure $3 A$. We observed a significant interaction between training days and FosGFP expression in the test groups $\left(F_{(1,53)}=5.5, p=0.023\right)$, but not in the no test groups $\left(F_{(1,37)}=1.5, p=0.23\right.$; Fig. $\left.3 C\right)$. Specifically, input resistance was increased from 1 to $10 \mathrm{~d}$ of training in $\mathrm{FosGFP}^{+}$, but not Fos$\mathrm{GFP}^{-}$, neurons in the test group rats. This increased input resistance likely contributes to the previously shown increased intrinsic excitability from 1 to $10 \mathrm{~d}$ of training in $\mathrm{GFP}^{+}$neurons from the test group rats given that there is a direct relationship between input resistance and voltage output. However, whereas input resistance was lower in FosGFP ${ }^{+}$than in FosGFP ${ }^{-}$neurons in day 1 test group rats, intrinsic excitability was not different between these two neuronal populations (Fig. 3B).

We also examined other potential modulators of intrinsic excitability. For resting membrane potential (Fig. 3C) and percentage sag current (Fig. 3D) in the test groups, there were no significant interactions between training day and FosGFP. However, we found a significant interaction between training day and FosGFP expression for percentage sag current in the no test groups $\left(F_{(1,37)}=4.6, p<0.05\right)$. Specifically, the percentage sag current in FosGFP ${ }^{+}$, but not FosGFP ${ }^{-}$, neurons decreased from 1 to $10 \mathrm{~d}$ of training.

\section{Alterations of single AP properties in $\mathrm{FosGFP}^{+}$and FosGFP ${ }^{-}$ PLC neurons after food self-administration}

We examined properties of single APs to determine whether a shift in these properties drives the reduction in excitability observed in FosGFP ${ }^{-}$neurons. We measured AP latency, amplitude, threshold, and half-width (Fig. 4C) in FosGFP ${ }^{+}$and FosGFP $^{-}$neurons in the test and no test groups on days 1 and 10 and found that none of these parameters was altered. We also measured rheobase current, which is defined as the amount of direct current injection required to elicit a single AP. In the test groups, we found a significant interaction between training day and FosGFP expression $\left(F_{(1,51)}=6.00, p<0.05\right)$. A Fisher PLSD test indicated that rheobase current was significantly greater in day 10 FosGFP $^{-}$neurons compared with day 1 FosGFP ${ }^{-}$neurons. In the no test groups, we found a significant main effect of FosGFP expression $\left(F_{(1,37)}=7.3, p<0.05\right)$, as well as a significant interaction between FosGFP expression and training day $\left(F_{(1,37)}=\right.$ $7.3, p<0.05)$. Fisher PLSD tests indicated that rheobase current was greater in day 10 FosGFP $^{-}$neurons compared with day 1 FosGFP ${ }^{-}$neurons and day $10 \mathrm{FosGFP}^{+}$neurons.

We next assessed mAHP in single APs; test parameters and sample traces are shown in Figure $4, A$ and $B$. In the test groups, we found significant main effects for training day $\left(F_{(1,5)}=11.9\right.$, $p=0.001)$ and FosGFP expression $\left(F_{(1,51)}=5.4, p=0.025\right.$; Fig. $4 C)$; the interaction between these two factors was not significant $\left(F_{(1,51)}=3.25, p=0.077\right)$. Fisher PLSD tests indicated that the $\mathrm{mAHP}$ in the FosGFP ${ }^{-}$neurons was significantly greater after day 10 than on day 1 of training in FosGFP ${ }^{-}$neurons or after days 1 or 10 in FosGFP ${ }^{+}$neurons (Fig. 4C). Although the interaction between training day and FosGFP expression was not sig- 


\section{A}

Representative PLC FosGFP+ neuron
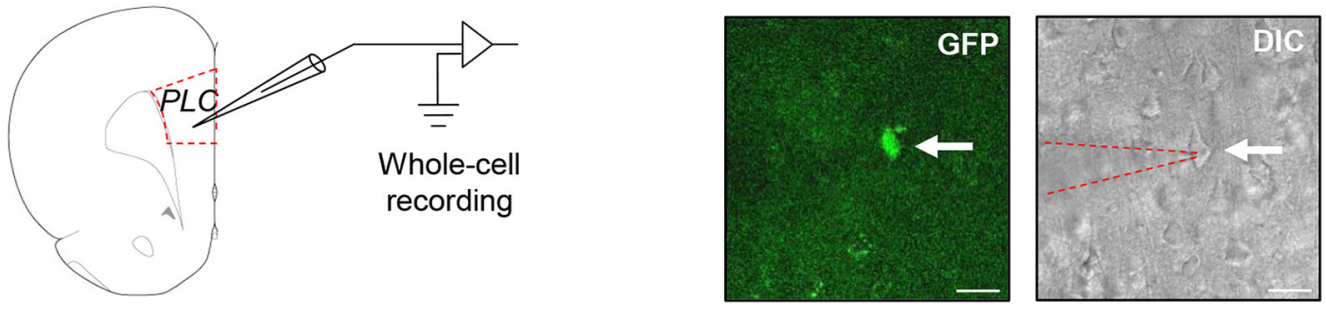

B

Representative traces PLC FosGFP- and FosGFP+ neurons

No test

Day 1
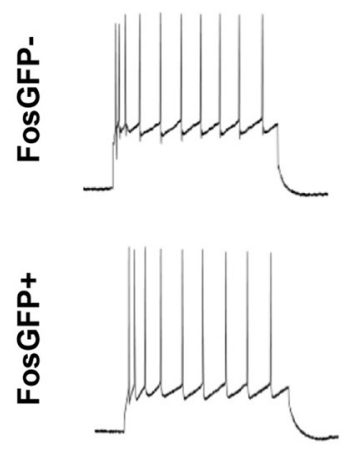

$3 \longdiv { \mathrm { pA } }$

Day 10
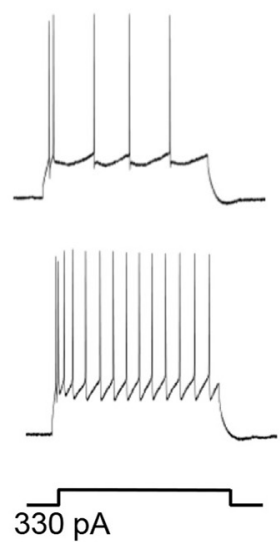

Test

Day 1

Day 10
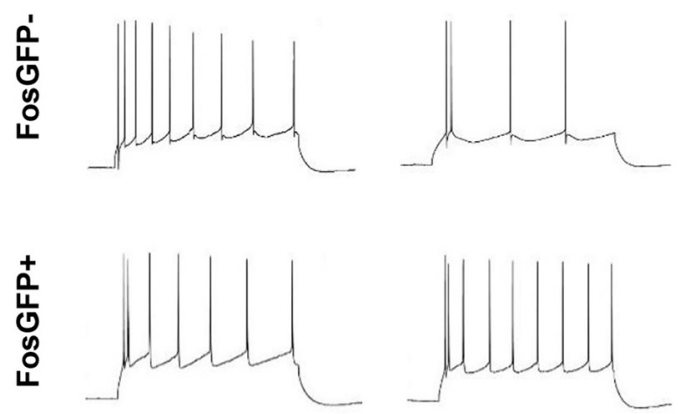

$200 \mathrm{~ms} 20$

C PLC FosGFP- and FosGFP+ intrinsic excitability: Input-output curve

No test

FosGFP-

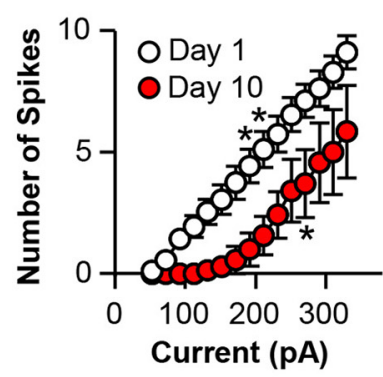

FosGFP+

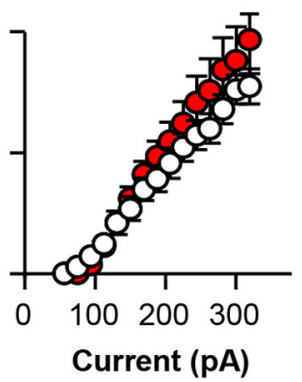

FosGFP-

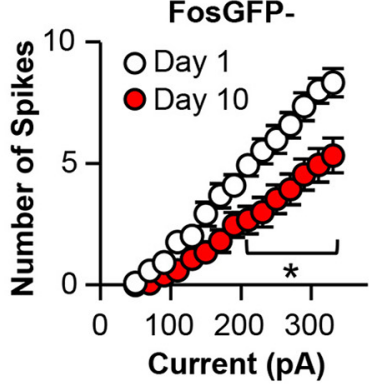

Test

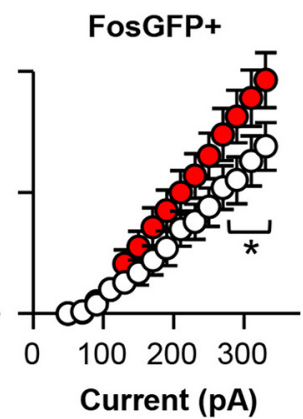

Figure 2. Bidirectional modulation of $\mathrm{PLC} \mathrm{FosGFP}^{+}$and FosGFP ${ }^{-}$neuronal excitability after food self-administration training. $\boldsymbol{A}$, Experimental configuration and representative image of FosGFP ${ }^{+}$neuron in PLC. DIC, Differential interference contrast). $B$, Example traces from FosGFP ${ }^{-}$and FosGFP ${ }^{+}$neurons in test and no test groups after somatic current injection. $C$, Input- output curves for FosGFP ${ }^{-}$and FosGFP ${ }^{+}$neurons in test and no test groups (different from day $1,{ }^{*} p<0.05 ;$ no test- day 1 FosGFP ${ }^{-}: n=16$ cells $/ 11$ rats; no test- day 1 FosGFP ${ }^{+}: n=12$ cells $/ 8$ rats; no test- day 10 FosGFP ${ }^{-}: n=7$ cells $/ 4$ rats; no test- day 10 FosGFP ${ }^{+}: n=8$ cells $/ 5$ rats; test- day 1 FosGFP ${ }^{-}: n=11$ cells $/ 9$ rats; test- day 1 FosGFP ${ }^{+}: 10$ cells $/ 7$ rats; test- day 10 FosGFP ${ }^{-}:$ $n=15$ cells/11 rats; test-day 10 FosGFP ${ }^{+}: n=16$ cells/11 rats).

nificant $\left(F_{(1,36)}=3.2, p=0.08\right)$, Fischer PLSD tests indicated that the $\mathrm{mAHP}$ in the $\mathrm{FosGFP}^{-}$neurons was significantly greater after day 10 than on day 1 of training in FosGFP ${ }^{-}$neurons or after days 1 or 10 in FosGFP ${ }^{+}$neurons (Fig. 4C).

We also measured fAHP and found no significant effects of training days or FosGFP expression in the test or no test groups. Altogether, these data indicate that mAHP is increased from 1 to $10 \mathrm{~d}$ of training in FosGFP ${ }^{-}$neurons, but not in FosGFP ${ }^{+}$neurons, which corresponds with our previously observed decrease of intrinsic excitability in FosGFP ${ }^{-}$neurons from 1 to $10 \mathrm{~d}$ of training.

SK channels are known to contribute to MAHP magnitude in cortical neurons (Alger et al., 1994; Sah and Faber, 2002). We used the selective SK channel antagonist apamin to study the role of SK channels in modulating the firing rate of FosGFP ${ }^{-}$PLC neurons from only the test group rats. First, we found that $300 \mathrm{nM}$ apamin had a greater effect on mAHP magnitude in FosGFP ${ }^{-}$ neurons after training day 10 than training day $1\left(t_{(17)}=2.9\right.$, $p=0.01$; Fig. $5 A, B)$. Next, we examined the contribution of SK channels to firing rate in FosGFP ${ }^{-}$neurons. We found a larger effect of $300 \mathrm{nM}$ apamin on the firing rate in FosGFP ${ }^{-}$neurons on training day 10 than training day $1\left(t_{(18)}=2.23, p=0.04\right.$; Fig. $\left.5 C, D\right)$. Altogether, these data suggest that SK channel upregulation from 1 to $10 \mathrm{~d}$ is responsible for the decreased intrinsic excitability observed in FosGFP ${ }^{-}$neurons from training day 1 to day 10. 
A

Representative traces: Input resistance

No test

Day 1
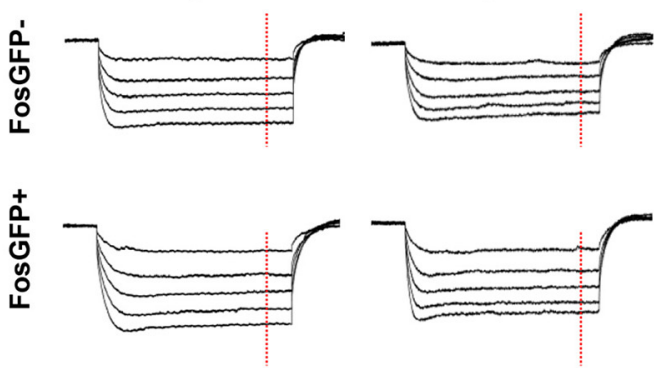

$20 \mathrm{mV}$

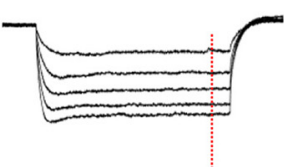

B

Input resistance

No test

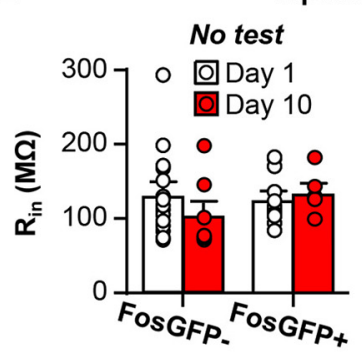

D

Day 1
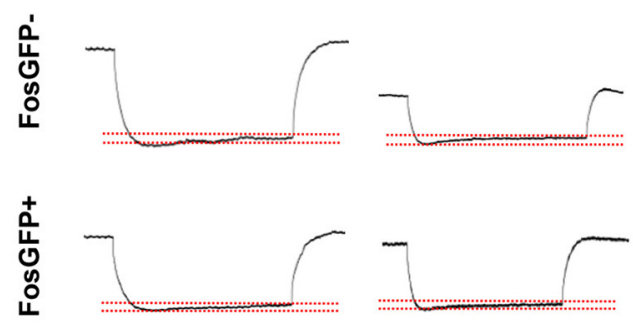

$\frac{10 \mathrm{mV}}{200 \mathrm{~ms}}$

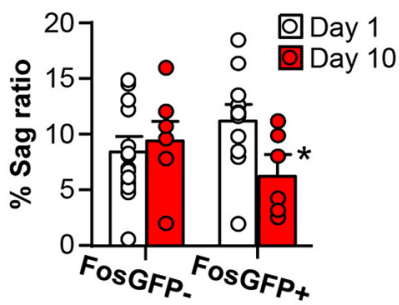

Test

Day 1
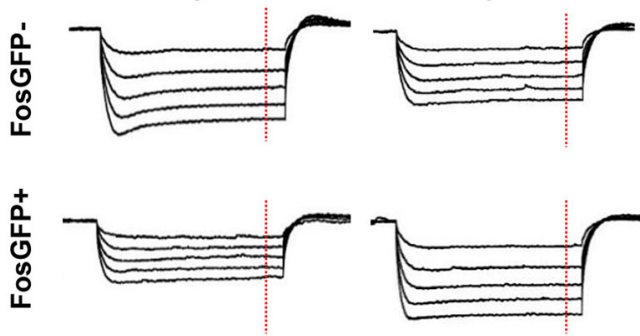

Day 10

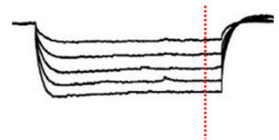

C

Resting membrane potential

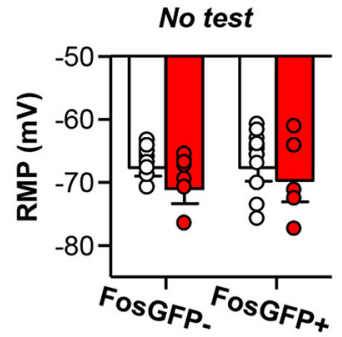

Test

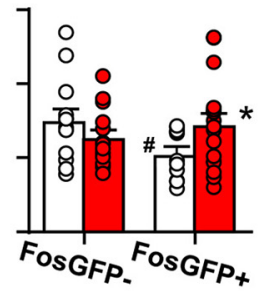

Test

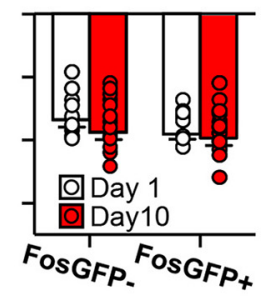

Representative traces: Sag current ratio

Day 10

Day 1
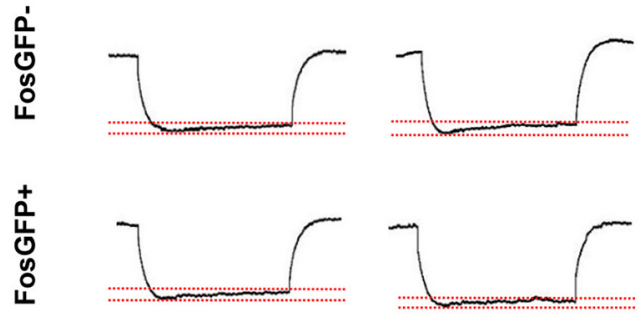

Figure 3. Subthreshold membrane properties of $\mathrm{PLC} \mathrm{FosGFP}^{+}$and FosGFP ${ }^{-}$neurons after food self-administration training. $A$, Representative traces showing measurement of input resistance using the slope of the $I-V$ curve after injections of hyperpolarizing current. $B$, Input resistance is significantly greater in FosGFP ${ }^{+}$neurons on day 10 than on day 1 . Input resistance in day 1 FosGFP ${ }^{+}$ neurons was lower than FosGFP- ${ }^{-}$neurons on day 1. C, Resting membrane potential remains consistent in both no test and test groups after operant training. $\boldsymbol{D}$, Example traces showing measurement of sag current ratio in FosGFP ${ }^{-}$and FosGFP ${ }^{+}$neurons in test and no test groups and summary graphs showing percentage sag ratio in no test and test groups. Sag current is reduced in the Day 10 FosGFP ${ }^{+}$neurons in the no test group but remains unchanged in the test group $\left({ }^{*} p<0.05\right.$, no test- day 1 FosGFP ${ }^{-}: n=16$ cells $/ 11$ rats; no test- day 1 FosGFP ${ }^{+}: n=12$ cells $/ 8$ rats; no test-day 10 FosGFP ${ }^{-}: n=7$ cells/4 rats; no test-day 10 FosGFP ${ }^{+}: n=8$ cells/5 rats; test-day 1 FosGFP ${ }^{-}: n=11$ cells/9 rats; test-day 1 FosGFP ${ }^{+}: 10$ cells/7 rats; test- day 10 FosGFP ${ }^{-}: n=15$ cells $/ 11$ rats; test- day 10 FosGFP $^{+}: n=16$ cells $/ 11$ rats). 
A Representative action potential (AP) trace from layer V PLC neuron

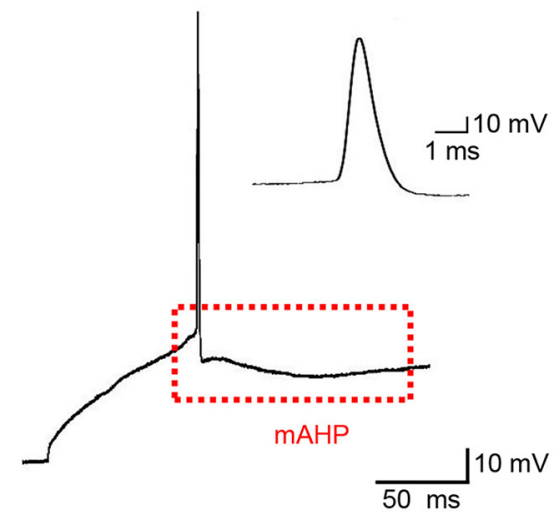

C

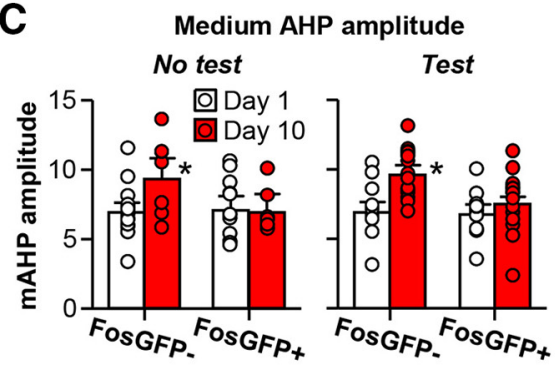

B Representative medium after-hyperpolarization (mAHP) traces

No test

Day 1

Day 10
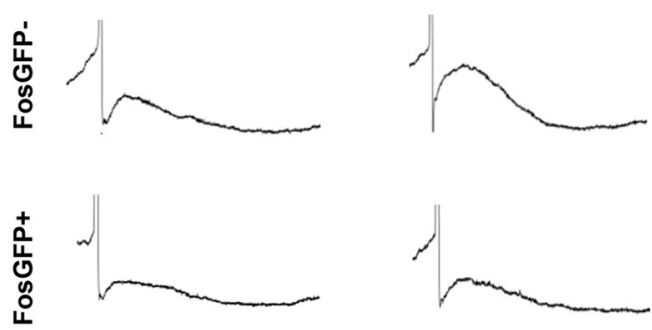

Test

Day 1
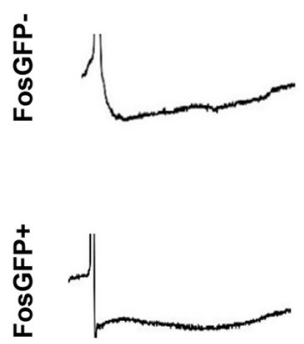

Day 10
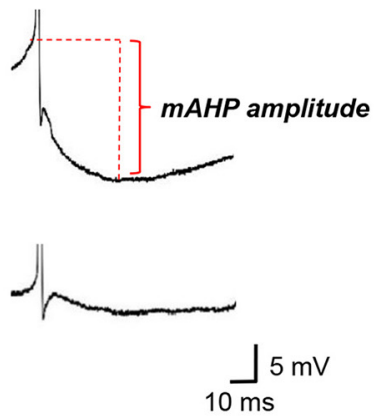

D
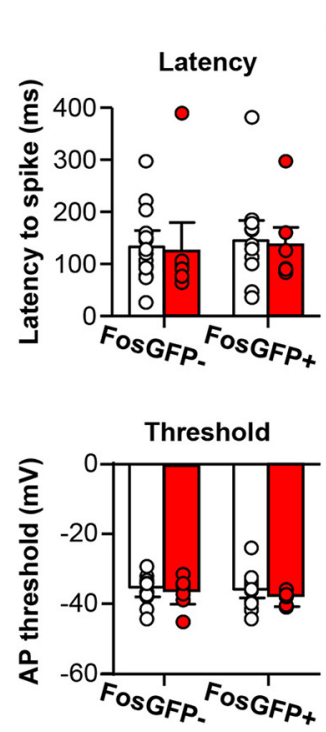

A. No test
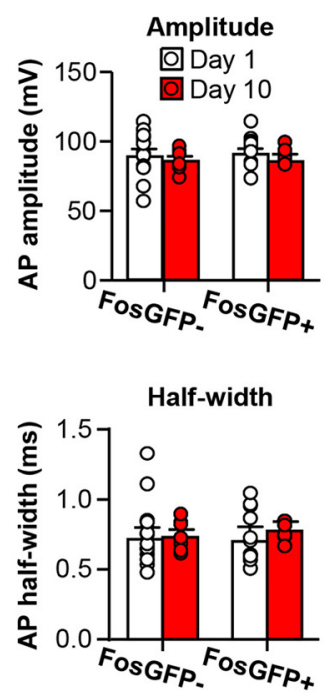

Action potential parameters

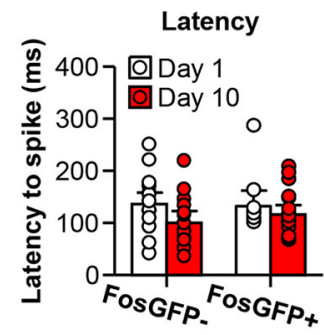

B. Test
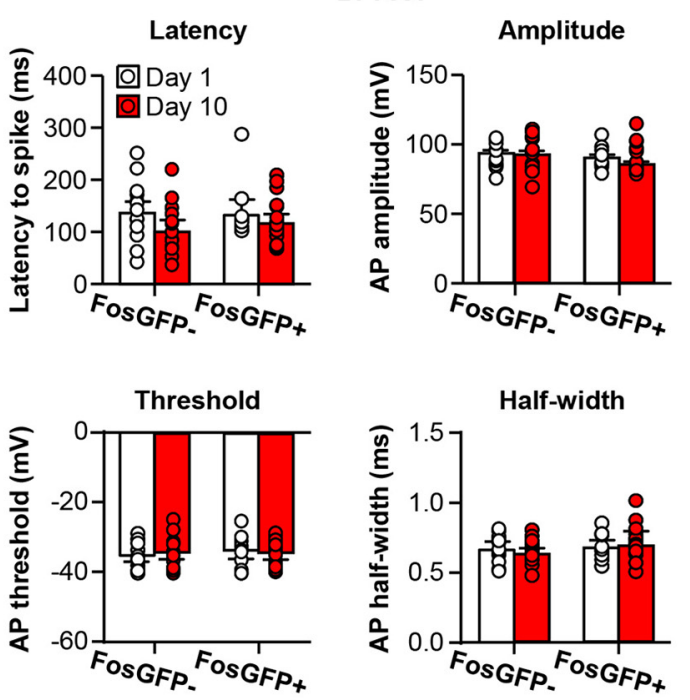

Figure 4. $\mathrm{mAHP}$ is increased in FosGFP ${ }^{-}$neurons on day 10 in both test and no test groups. $A$, Representative AP trace from FosGFP ${ }^{+}$neuron on two different time scales. Red dotted line shows the portion of the trace analyzed to determine the magnitude of the medium AHP. $B$, Example traces of mAHP currents (AP is truncated) in FosGFP ${ }^{-}$and FosGFP ${ }^{+}$neurons in test and no test groups. C, mAHP amplitude is enhanced exclusively in FosGFP ${ }^{-}$Day 10 neurons in both the test and no test groups $\left({ }^{*} p<0.05 ;\right.$ no test - day 1 FosGFP ${ }^{-}: n=16$ cells $/ 11$ rats; no test- day 1 FosGFP ${ }^{+}: n=$ 12 cells/ 8 rats; no test-day 10 FosGFP ${ }^{-}: n=7$ cells $/ 4$ rats; no test- day 10 FosGFP ${ }^{+}: n=8$ cells $/ 5$ rats; test- day 1 FosGFP ${ }^{-}: n=11$ cells $/ 9$ rats; test- day 1 FosGFP ${ }^{+}: 10$ cells $/ 7$ rats; test- day 10 FosGFP $^{-}: n=15$ cells $/ 11$ rats; test-day 10 FosGFP ${ }^{+}: n=16$ cells/11 rats). $D$, AP parameters remain unchanged in no test and test groups ( $p>0.05$ for all groups and comparisons, no test-day 1 FosGFP ${ }^{-}: n=16$ cells $/ 11$ rats; no test-day 1 FosGFP ${ }^{+}: n=12$ cells $/ 8$ rats; no test-day 10 FosGFP ${ }^{-}: n=7$ cells $/ 4$ rats; no test- day 10 FosGFP ${ }^{+}: n=8$ cells $/ 5$ rats; test- day 1 FosGFP ${ }^{-}: n=11$ cells/9 rats; test- day 1 FosGFP ${ }^{+}: 10$ cells $/ 7$ rats; test- day 10 FosGFP ${ }^{-}: n=15$ cells $/ 11$ rats; test- day 10 FosGFP ${ }^{+}: n=16$ cells $/ 11$ rats).

Role of PLC SK channels in food-seeking behavior

We injected the SK channel antagonist apamin into PLC to assess whether increased SK channel function in the Fos $\mathrm{GFP}^{-}$neurons plays a causal role in the expression of food-seeking behavior. It should be noted that the FosGFP ${ }^{-}$neuronal population comprises $\sim 95 \%$ of all neurons in PLC because FosGFP ${ }^{+}$neurons comprise just $5 \%$ of the population (see above) and that a difference in the MAHP current mediated by SK channels was observed 
A SK channel antagonist effect on mAHP in FosGFP- neurons
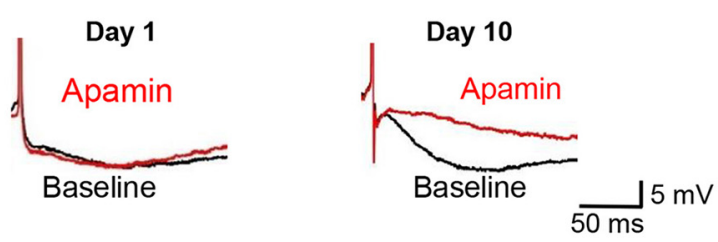

C Representative traces following SK channel antagonism in FosGFP-neurons
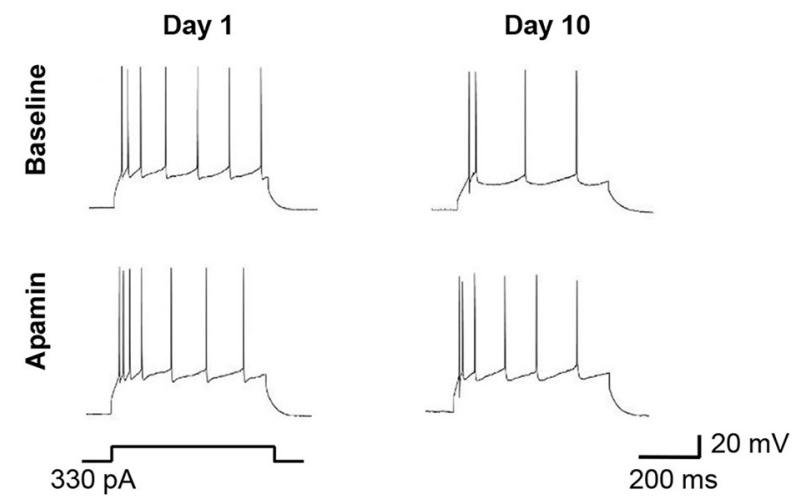

B SK channel contribution to MAHP in FosGFP- neurons

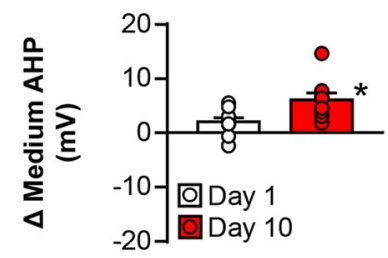

D Effect of SK channel antagonism on spike rate in FosGFP- neurons

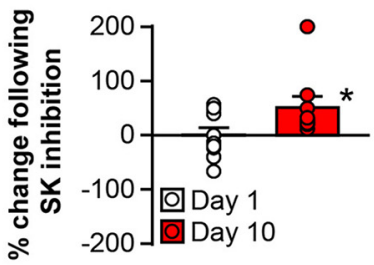

Figure 5. Enhanced contribution of $S K$ channels in nonactivated population of neurons after operant learning. $A, B$, Example traces showing the effect of $S K$ channel antagonism on $m A H P$ currents in FosGFP ${ }^{-}$neurons in the test group. Summary graph shows larger SK contribution to the mAHP in day 10 FosGFP ${ }^{-}$neurons $\left(^{*} p<0.05\right.$, day 1 FosGFP ${ }^{-}: n=10$ cells/6 rats; day 10 FosGFP ${ }^{-}: n=9$ cells $/ 6$ rats). C, Example traces showing larger effect of SK channel antagonism on repetitive firing in FosGFP ${ }^{-}$day 10 neurons from the test group. $D$, Summary graph showing the percentage increase in firing after SK channel antagonism in FosGFP ${ }^{-}$neurons $\left({ }^{*} p<0.05\right.$, day 1 FosGFP ${ }^{-}: n=10$ cells $/ 6$ rats; day 10 FosGFP $^{-}: n=9$ cells $/ 6$ rats).

only in $\mathrm{FosGFP}^{-}$neurons and not in FosGFP ${ }^{+}$neurons. We first trained rats to lever press for palatable food pellets for $12 \mathrm{~d}$ using the same training procedure as before (Fig. $6 A, B$ ). On the $13^{\text {th }}$ day, we injected $0.5 \mu \mathrm{g} / 0.5 \mu \mathrm{l} /$ side apamin or vehicle into PLC (Fig. 6C) immediately before a 30 min test session conducted under extinction conditions. Active lever presses were not altered significantly by intra-PLC administration of vehicle or apamin $\left(t_{16)}=1.57, p=0.13\right.$; Fig. $\left.6 D\right)$. To confirm that blocking SK channels had an effect on neuronal excitability, we quantified Fos expression in PLC after intra-PLC administration of apamin or vehicle (Fig. $6 E$ ). Fos expression was increased $\sim 3$-fold after intra-PLC administration of apamin $\left(t_{(16)}=3.98, p=0.001\right.$; Fig. $6 E)$. Altogether, these data suggest that decreased excitability of FosGFP $^{-}$neurons (mediated by increased SK channels) in PLC does not play a causal role in the expression of food-seeking behavior.

\section{Discussion}

Food self-administration training induced opposing effects on intrinsic excitability in the small number of Fos-expressing neurons that play a causal role in operant food-seeking behavior compared with excitability in the majority of PLC neurons that were Fos ${ }^{-}$. Daun02 inactivation of Fos-expressing neurons that were activated selectively during operant food self-administration decreased subsequent non-reinforced food-seeking behavior. The causal role of these neurons in food seeking suggests they may be altered uniquely to encode food-associated memories. Increased excitability of Fos-expressing neurons was likely driven by an increase in steady-state input resistance. In contrast, food self-administration training decreased excitability of Fos ${ }^{-}$neurons through an increase in the contribution of SK channels. Injections of the SK channel blocker apamin in PLC produced a robust increase of neural activity in this brain area, but had no effect on food-seeking behavior. This finding reinforces the conclusion that functional alterations within Fos-expressing ensembles play a unique and important role in encoding food-seeking behavior.

Fos-expressing neuronal ensembles in PLC contribute to the expression of operant learning

Selective inactivation of Fos-expressing neurons in PLC attenuated food seeking. Only 5\% of NeuN-labeled neurons in PLC coexpressed Fos after self-administration training. Previous Daun 02 inactivation studies have shown that $1-10 \%$ of neurons in immunohistochemical sections were $\mathrm{Fos}^{+}$and that these selectively activated Fos-expressing ensembles played a causal role in learned operant food (Suto et al., 2016; Warren et al., 2016) and drug (Bossert et al., 2011; Fanous et al., 2012; Cruz et al., 2014; Pfarr et al., 2015; Funk et al., 2016; de Guglielmo et al., 2016; Caprioli et al., 2017) seeking, as well as Pavlovian associations between drug and environmental cues (Koya et al., 2009). Similar findings have been reported for Fos-expressing ensembles in other Pavlovian learned behaviors in mice (Reijmers et al., 2007; Liu et al., 2012; Mayford and Reijmers, 2015; Tonegawa et al., 2015). Altogether, these studies support the hypothesis that behaviorally relevant learned associations are encoded by sparsely distributed Fos-expressing neuronal ensembles that are activated selectively during learning (Cruz et al., 2013; Cruz et al., 2015).

\section{Intrinsic excitability alterations within Fos-expressing} neuronal ensembles in PLC after operant learning

Based on the causal role of Fos-expressing ensembles in food self-administration and other operant learned behaviors, we hypothesized that unique alterations (or neuroadaptations) may be induced within these neurons that alter their responsivity dur- 
ing the learning process. We identified an increase in intrinsic excitability in the $\mathrm{Fos}^{+}$population of neurons in PLC after $10 \mathrm{~d}$ of food self-administration training. This effect is most likely driven by the concomitant increase in steady-state input resistance observed in $\mathrm{Fos}^{+}$neurons because there is a direct relationship between input resistance and voltage output. To our knowledge, this is the first demonstration of intrinsic plasticity in Fos expression ensembles after operant training. Recently, Ziminski et al. (2017) demonstrated increased excitability in Fos-expressing neurons of the nucleus accumbens shell after exposure to sucrosepredictive cues; this difference in excitability was no longer present after extinction training. Overall, these data suggest that neuronal excitability in activity-driven ensembles may be regulated dynamically to encode learning and memory.

Yiu et al. (2014) used viral overexpression of CREB to increase neuronal excitability in a small population of neurons in the lateral amygdala before fear conditioning. CREB overexpression enhanced allocation of these neurons into neuronal ensembles mediating the fear memory, which suggested that neurons might be recruited selectively to a unique ensemble based on their level of intrinsic excitability immediately before training. However, our data suggest that, in a behaviorally activated neuronal ensemble rather than in an artificially recruited ensemble, there is no preferential recruitment of more excitable neurons because we did not observe a baseline difference between $\mathrm{Fos}^{+}$and Fos $^{-}$neurons in the no test control group on day 1. Previously, we found altered synaptic function in Fosexpressing neuronal ensembles after Pavlovian drug-associated learning (Koya et al., 2012; Whitaker et al., 2016) and yohimbineinduced reinstatement of food seeking (Cifani et al., 2012).

Our results agree with data suggesting that coding changes in frontal cortex neurons may represent a mechanism by which associative memory is stored (Takehara-Nishiuchi and McNaughton, 2008). It has also been suggested that PLC plays a critical role in the acquisition but not the expression of operant learning (Baldwin et al., 2002; Corbit and Balleine, 2003). However, these studies used region-wide inactivation to examine the role of PLC in operant training. Targeting the specific neuronal population active during the expression of operant learning reveals a critical role for PLC that was unknown previously. One possible scenario is that different neuronal ensembles intermingle within PLC that encode separate learned associations or memories (Warren et al., 2016). This seems likely given the diverse role of PLC in attentional allocation, contextual encoding, and rewarding and aversive learning (Watanabe, 1996; Schall et al., 2002; Fujii and Graybiel, 2003; Euston et al., 2012; Sharpe and Killcross, 2014; Pinto and Dan, 2015). In support of this idea, recently, we demonstrated a critical role of infralimbic cortex (ILC) neuronal ensembles in both operant learning and extinction of the operant

\section{B Self-Administration}
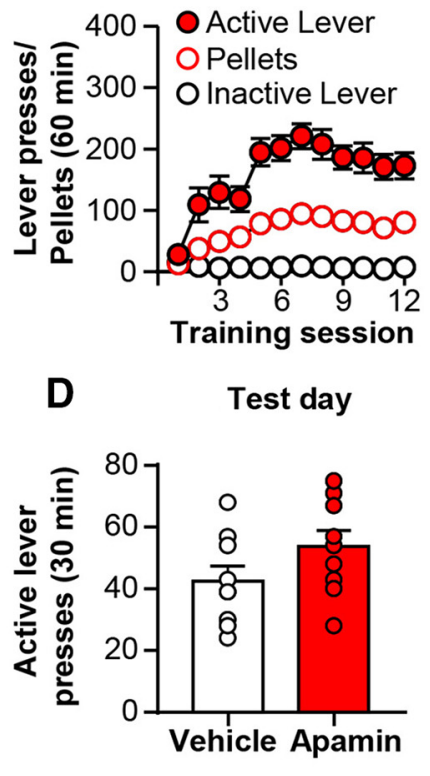

D

Test day
PLC - Vehicle or Apamin injection

placement

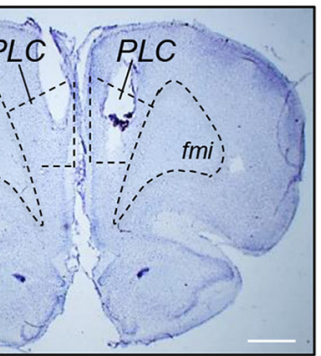

Figure 6. Intra-PLC administration of the SK channel antagonist apamin has no effect on the expression of operant learning $\boldsymbol{A}, \boldsymbol{B}$, Experimental timeline and food self-administration behavior. $\boldsymbol{C}$, Cannula placement for in vivo apamin experiment. $\boldsymbol{D}$, Lever-pressing behavior on test day (vehicle: $n=9$, Apamin $n=9 ; \boldsymbol{E}$ ). Representative images of Fos expression and Fos quantification after in vivo treatment with apamin are shown $\left({ }^{*} p<0.05\right.$; vehicle: $n=9$, Apamin $n=9$ ).

response (Warren et al., 2016). Pfarr et al. (2015) also demonstrated a role for Fos-expressing ensembles of ILC in suppression of cue-induced alcohol seeking. Interestingly, nonselective inactivation of ILC did not recapitulate these effects. Together, these data suggest that targeting activity-dependent neuronal ensembles will help to elucidate the complex role of various brain regions in learned behaviors.

We also identified a decrease in intrinsic excitability in the Fos ${ }^{-}$population of neurons, which comprise the majority of the area's neurons, in PLC after food self-administration training. This effect was present in both no test and test groups, suggesting that this decrease in excitability occurs gradually over the course of training rather than being acutely induced on the tenth day of training. We found that $\mathrm{mAHP}$ amplitude was increased in PLC Fos $^{-}$neurons on day 10 of training in both test and no test groups and that blocking SK channels reversed this alteration in mAHP amplitude and firing rate, suggesting that an increased contribution of the SK channel drives the decrease in excitability that we observed. The modulation of neuronal excitability has also been demonstrated after operant training for alcohol and cocaine (Hopf et al., 2010; Chen et al., 2013). Chen et al. (2013) demonstrated hypoexcitability in layer $\mathrm{V}$ pyramidal neurons after cocaine self-administration that was driven by a decrease in 
input resistance. Hopf et al. (2010) identified heightened excitability in medium spiny neurons of the nucleus accumbens core after ethanol self-administration that was mediated by a decrease in the expression of the SK3 channel. Therefore, there is precedent for altered intrinsic excitability in the majority of neurons after operant learning. Furthermore, modulation of the SK channel may represent a common mechanism through which experience-dependent plasticity in most neurons is induced. Given that neuronal output is shaped by the interaction between both intrinsic and synaptic properties (Kourrich et al., 2015), this will be an important area for future research.

\section{Conclusions}

We observed bidirectional modulation of excitability in Fosexpressing neuronal ensembles and Fos ${ }^{-}$nonensembles in PLC. Excitability in Fos $^{+}$neurons increased from 1 to $10 \mathrm{~d}$ of food self-administration, whereas excitability decreased in the Fos ${ }^{-}$ neurons that comprise most neurons in this brain area. The Daun02 inactivation data indicate that the Fos-expressing neurons mediate learned food-seeking behavior. Therefore, increased intrinsic excitability within these neurons during learning is likely to play an important role in operant memory formation. Decreased excitability in the Fos ${ }^{-}$neurons may be due to decreased novelty over time or habituation to signals that were unnecessary for obtaining the food reward. Our recordings were restricted to layer $\mathrm{V}$ pyramidal neurons because these are the primary output neurons of the PLC that can affect downstream circuitry and behavior (Narayanan and Laubach, 2006). Because both $\mathrm{Fos}^{+}$and Fos ${ }^{-}$neuronal populations varied widely in their intrinsic properties, there might be different populations of output neurons with varied projection targets (Dembrow et al., 2010; Guan et al., 2015) that are important for controlling different components of operant learned behaviors. Future studies are needed to determine the specific downstream targets of Fosexpressing ensembles that are causally involved in the expression of operant learning.

Note Added in Proof: Jennifer Beidel should be included in the author list. Her name was accidentally omitted from the revised version of the manuscript. It is now included.

\section{References}

Alger BE, Sim JA, Brown DA (1994) Single-channel activity correlated with medium-duration, Ca-dependent $\mathrm{K}$ current in cultured rat hippocampal neurones. Neurosci Lett 168:23-28. CrossRef Medline

Baldwin AE, Sadeghian K, Kelley AE (2002) Appetitive instrumental learning requires coincident activation of NMDA and dopamine D1 receptors within the medial prefrontal cortex. J Neurosci 22:1063-1071. Medline

Beck H, Yaari Y (2008) Plasticity of intrinsic neuronal properties in CNS disorders. Nat Rev Neurosci 9:357-369. CrossRef Medline

Bossert JM, Stern AL, Theberge FR, Cifani C, Koya E, Hope BT, Shaham Y (2011) Ventral medial prefrontal cortex neuronal ensembles mediate context-induced relapse to heroin. Nat Neurosci 14:420-422. CrossRef Medline

Brons JF, Woody CD (1980) Long-term changes in excitability of cortical neurons after Pavlovian conditioning and extinction. J Neurophysiol 44: 605-615. Medline

Calu DJ, Chen YW, Kawa AB, Nair SG, Shaham Y (2014) The use of the reinstatement model to study relapse to palatable food seeking during dieting. Neuropharmacology 76:395-406. CrossRef Medline

Cannady R, McGonigal JT, Newsom RJ, Woodward JJ, Mulholland PJ, Gass JT (2017) Prefrontal cortex KCa2 channels regulate mGlu5-dependent plasticity and extinction of alcohol-seeking behavior. J Neurosci 37:43594369. CrossRef Medline

Caprioli D, Venniro M, Zhang M, Bossert JM, Warren BL, Hope BT, Shaham Y (2017) Role of dorsomedial striatum neuronal ensembles in incubation of methamphetamine craving after voluntary abstinence. J Neurosci 37:1014-1027. CrossRef Medline
Chen BT, Yau HJ, Hatch C, Kusumoto-Yoshida I, Cho SL, Hopf FW, Bonci A (2013) Rescuing cocaine-induced prefrontal cortex hypoactivity prevents compulsive cocaine seeking. Nature 496:359-362. CrossRef Medline

Cifani C, Koya E, Navarre BM, Calu DJ, Baumann MH, Marchant NJ, Liu QR Khuc T, Pickel J, Lupica CR, Shaham Y, Hope BT (2012) Medial prefrontal cortex neuronal activation and synaptic alterations after stressinduced reinstatement of palatable food seeking: a study using c-fos-GFP transgenic female rats. J Neurosci 32:8480-8490. CrossRef Medline

Corbit LH, Balleine BW (2003) The role of prelimbic cortex in instrumental conditioning. Behav Brain Res 146:145-157. CrossRef Medline

Cruz FC, Koya E, Guez-Barber DH, Bossert JM, Lupica CR, Shaham Y, Hope BT (2013) New technologies for examining the role of neuronal ensembles in drug addiction and fear. Nat Rev Neurosci 14:743-754. CrossRef Medline

Cruz FC, Babin KR, Leao RM, Goldart EM, Bossert JM, Shaham Y, Hope BT (2014) Role of nucleus accumbens shell neuronal ensembles in contextinduced reinstatement of cocaine-seeking. J Neurosci 34:7437-7446. CrossRef Medline

Cruz FC, Javier Rubio F, Hope BT (2015) Using c-fos to study neuronal ensembles in corticostriatal circuitry of addiction. Brain Res 1628:157173. CrossRef Medline

de Guglielmo G, Crawford E, Kim S, Vendruscolo LF, Hope BT, Brennan M, Cole M, Koob GF, George O (2016) Recruitment of a neuronal ensemble in the central nucleus of the amygdala is required for alcohol dependence. J Neurosci 36:9446-9453. CrossRef Medline

Dembrow NC, Chitwood RA, Johnston D (2010) Projection-specific neuromodulation of medial prefrontal cortex neurons. J Neurosci 30:1692216937. CrossRef Medline

Engeln M, Bastide MF, Toulmé E, Dehay B, Bourdenx M, Doudnikoff E, Li Q, Gross CE, Boué-Grabot E, Pisani A, Bezard E, Fernagut PO (2016) Selective inactivation of striatal FosB/DeltaFosB-expressing neurons alleviates L-DOPA-induced dyskinesia. Biol Psychiatry 79:354-361. CrossRef Medline

Euston DR, Gruber AJ, McNaughton BL (2012) The role of medial prefrontal cortex in memory and decision making. Neuron 76:1057-1070. CrossRef Medline

Fanous S, Goldart EM, Theberge FR, Bossert JM, Shaham Y, Hope BT (2012) Role of orbitofrontal cortex neuronal ensembles in the expression of incubation of heroin craving. J Neurosci 32:11600-11609. CrossRef Medline

Fujii N, Graybiel AM (2003) Representation of action sequence boundaries by macaque prefrontal cortical neurons. Science 301:1246-1249. CrossRef Medline

Funk D, Coen K, Tamadon S, Hope BT, Shaham Y, Lê AD (2016) Role of central amygdala neuronal ensembles in incubation of nicotine craving. J Neurosci 36:8612-8623. CrossRef Medline

Giustino TF, Fitzgerald PJ, Maren S (2016) Fear expression suppresses medial prefrontal cortical firing in rats. PLoS One 11:e0165256. CrossRef Medline

Guan D, Armstrong WE, Foehring RC (2015) Electrophysiological properties of genetically identified subtypes of layer 5 neocortical pyramidal neurons: $\mathrm{Ca}(2)(+)$ dependence and differential modulation by norepinephrine. J Neurophysiol 113:2014-2032. Medline

Hebb DO (1949) The organization of behavior: a neuropsychological theory. New York: Wiley.

Hopf FW, Bowers MS, Chang SJ, Chen BT, Martin M, Seif T, Cho SL, Tye K, Bonci A (2010) Reduced nucleus accumbens SK channel activity enhances alcohol seeking during abstinence. Neuron 65:682-694. CrossRef Medline

Kourrich S, Calu DJ, Bonci A (2015) Intrinsic plasticity: an emerging player in addiction. Nat Rev Neurosci 16:173-184. CrossRef Medline

Koya E, Golden SA, Harvey BK, Guez-Barber DH, Berkow A, Simmons DE, Bossert JM, Nair SG, Uejima JL, Marin MT, Mitchell TB, Farquhar D, Ghosh SC, Mattson BJ, Hope BT (2009) Targeted disruption of cocaineactivated nucleus accumbens neurons prevents context-specific sensitization. Nat Neurosci 12:1069-1073. CrossRef Medline

Koya E, Cruz FC, Ator R, Golden SA, Hoffman AF, Lupica CR, Hope BT (2012) Silent synapses in activated selectively nucleus accumbens neurons following cocaine sensitization. Nat Neurosci 15:1556-1562. CrossRef Medline

Liu X, Ramirez S, Pang PT, Puryear CB, Govindarajan A, Deisseroth K, Tonegawa S (2012) Optogenetic stimulation of a hippocampal engram activates fear memory recall. Nature 484:381-385. CrossRef Medline 
Matsumoto M, Matsumoto K, Abe H, Tanaka K (2007) Medial prefrontal cell activity signaling prediction errors of action values. Nat Neurosci 10:647-656. CrossRef Medline

Mayford M, Reijmers L (2015) Exploring memory representations with activity-based genetics. Cold Spring Harb Perspect Biol 8:a021832. CrossRef Medline

Moorman DE, Aston-Jones G (2015) Prefrontal neurons encode contextbased response execution and inhibition in reward seeking and extinction. Proc Natl Acad Sci U S A 112:9472-9477. CrossRef Medline

Morgan JI, Curran T (1986) Role of ion flux in the control of c-fos expression. Nature 322:552-555. CrossRef Medline

Narayanan NS, Laubach M (2006) Top-down control of motor cortex ensembles by dorsomedial prefrontal cortex. Neuron 52:921-931. CrossRef Medline

Oh MM, Disterhoft JF (2015) Increased excitability of both principal neurons and interneurons during associative learning. Neuroscientist 21: 372-384. CrossRef Medline

Pfarr S, Meinhardt MW, Klee ML, Hansson AC, Vengeliene V, Schönig K, Bartsch D, Hope BT, Spanagel R, Sommer WH (2015) Losing control: excessive alcohol seeking after selective inactivation of cue-responsive neurons in the infralimbic cortex. J Neurosci 35:10750-10761. CrossRef Medline

Pinto L, Dan Y (2015) Cell-type-specific activity in prefrontal cortex during goal-directed behavior. Neuron 87:437-450. CrossRef Medline

Reijmers LG, Perkins BL, Matsuo N, Mayford M (2007) Localization of a stable neural correlate of associative memory. Science 317:1230-1233. CrossRef Medline

Sah P, Faber ES (2002) Channels underlying neuronal calcium-activated potassium currents. Prog Neurobiol 66:345-353. CrossRef Medline

Schall JD, Stuphorn V, Brown JW (2002) Monitoring and control of action by the frontal lobes. Neuron 36:309-322. CrossRef Medline

Sharpe MJ, Killcross S (2014) The prelimbic cortex contributes to the downregulation of attention toward redundant cues. Cereb Cortex 24:10661074. CrossRef Medline
Song C, Ehlers VL, Moyer JR Jr (2015) Trace fear conditioning differentially modulates intrinsic excitability of medial prefrontal cortex-basolateral complex of amygdala projection neurons in infralimbic and prelimbic cortices. J Neurosci 35:13511-13524. CrossRef Medline

Suto N, Laque A, De Ness GL, Wagner GE, Watry D, Kerr T, Koya E, Mayford MR, Hope BT, Weiss F (2016) Distinct memory engrams in the infralimbic cortex of rats control opposing environmental actions on a learned behavior. Elife 5 .

Takehara-Nishiuchi K, McNaughton BL (2008) Spontaneous changes of neocortical code for associative memory during consolidation. Science 322:960-963. CrossRef Medline

Tonegawa S, Liu X, Ramirez S, Redondo R (2015) Memory engram cells have come of age. Neuron 87:918-931. CrossRef Medline

Warren BL, Mendoza MP, Cruz FC, Leao RM, Caprioli D, Rubio FJ, Whitaker LR, McPherson KB, Bossert JM, Shaham Y, Hope BT (2016) Distinct Fos-expressing neuronal ensembles in the ventromedial prefrontal cortex mediate food reward and extinction memories. J Neurosci 36:6691-6703. CrossRef Medline

Watanabe M (1996) Reward expectancy in primate prefrontal neurons. Nature 382:629-632. CrossRef Medline

Whitaker LR, Carneiro de Oliveira PE, McPherson KB, Fallon RV, Planeta CS, Bonci A, Hope BT (2016) Associative learning drives the formation of silent synapses in neuronal ensembles of the nucleus accumbens. Biol Psychiatry 80:246-256. CrossRef Medline

Yiu AP, Mercaldo V, Yan C, Richards B, Rashid AJ, Hsiang HL, Pressey J, Mahadevan V, Tran MM, Kushner SA, Woodin MA, Frankland PW, Josselyn SA (2014) Neurons are recruited to a memory trace based on relative neuronal excitability immediately before training. Neuron 83: 722-735. CrossRef Medline

Ziminski JJ, Hessler S, Margetts-Smith G, Sieburg MC, Crombag HS, Koya E (2017) Changes in appetitive associative strength modulates nucleus accumbens, but not orbitofrontal cortex neuronal ensemble excitability. J Neurosci 37:3160-3170. CrossRef Medline 